\title{
La ciudad hispanoamericana fragmentada versus su sostenibilidad ${ }^{*}$
}

\author{
Recibido: 28 de marzo de 2020 - Aprobado: 16 de abril de 2020 \\ https://doi.org/10.22395/seec.v23n54a3
}

Miroslawa Czerny
Andrzej Czerny

\section{RESUMEN}

La ciudad hispanoamericana, con rasgos estructurales muy característicos y duraderos, está pasando por profundos cambios en su diseño urbanístico y en su esquema funcional interno. De un modelo simple de su estructura socio-funcional-espacial se convierte en un patchwork de funciones, diseños arquitectónicos y niveles de servicios. La ciudad aparece cada vez más fragmentada en su tejido urbano, toma la forma de fragmentos separados de un espacio que no unen casi nada y que representan nuevos terrenos para la urbanización. El propósito de este artículo es identificar los principales determinantes de la fragmentación en el espacio geográfico de la ciudad hispanoamericana. Para ello, se empleó una metodología cualitativa que combina la revisión documental con el análisis de los procesos espaciales ocurridos durante las últimas cinco décadas en las ciudades hispanoamericanas. Los hallazgos de este trabajo indican que los principales determinantes de la fragmentación en el espacio geográfico son la fricción y la distancia psicológica, social y económica. Se requiere, entonces, una política urbana integral que suavice la fragmentación en estas ciudades.

\section{PALABRAS CLAVE}

Urbanización; fragmentación urbana; nuevo modelo de ciudad latinoamericana; zonas industriales; industrialización por sustitución de importaciones.

\section{CLASIFICACIÓN JEL}

J11, 018, R14, R31

\section{CONTENIDO}

Introducción; 1. Premisa de la fragmentación; 2. Fragmentación y globalización; 3. Conclusiones; Bibliografía.

- El texto ha sido preparado con base en una investigación independiente sobre los procesos internos en grandes ciudades latinoamericanas, realizada en la Universidad de Varsovia.

* Geógrafa, magíster en Geografía y doctora en Ciencias, Universidad de Varsovia, Varsovia, Polonia. Docente investigadora, Facultad de Estudios Regionales, Universidad de Varsovia, Varsovia, Polonia. Correo electrónico: mczerny@uw.edu.pl. Orcid: https://orcid.org/0000-0002-8216-9912

*. Geógrafo y magíster en Geografía, especialización Cartografía, Universidad de Varsovia, Polonia. Doctor en Ciencias de la Tierra, Academia de Ciencia de Polonia, Varsovia, Polonia. Docente investigador, Facultad de Ciencias de la Tierra y Manejo Territorial, Institute of Socio-Economic Geography and Spatial Management, Lublin, Polonia. Correo electrónico: aczerny@poczta.umcs.lublin.pl. Orcid: https://orcid. org/0000-0001-7006-1990 


\section{THE FRAGMENTED HISPANIC-AMERICAN CITY VERSUS ITS SUSTAINABILITY ABSTRACT}

The Hispanic-American city, with its structural, long-lasting, and characteristics features is going through deep changes in its urban design and in its internal functioning scheme. From a simple model of its social-functional-spatial structure, it becomes a patchwork of functions, architectural designs and levels of service. The city appears to be ever more fragmented in its urban tissue, takes the shape of fragments separated from a space held together by almost nothing and representing new grounds for urbanization. The purpose of this article is identifying the main determinants for the fragmentation of the Hispanic-American geographical space. For that, this research employed a qualitative methodology combined with the analysis of the spatial processes occurred within the last five decades in the Hispanic-American cities. The findings of this work indicate that the main determinants of the fragmentation in the geographical space are the friction and the psychological, social and economic distance. Therefore, it requires an integral urban policy that smooth the fragmentation in these cities.

\section{KEYWORDS}

Urban planning; urban fragmentation; new model of Hispanic-American city; industrial zones; import substitution industrialization.

\section{JEL CLASSIFICATION}

J11, 018, R14, R31

\section{CONTENT}

Introduction; 1. The premise of the fragmentation; 2. Fragmentation and globalization; 3. Conclusions; Bibliography.

\section{A CIDADE HISPANO-AMERICANA FRAGMENTADA VERSUS SUA SUSTENTABILIDADE RESUMO}

A cidade hispano-americana, com traços estruturais muito característicos e duradouros, está passando por profundas mudanças em seu desenho urbanístico e em seu esquema funcional interno. De um modelo simples de sua estrutura sociofuncional-espacial se converte em um patchwork de funções, desenhos arquitetônicos e níveis de serviços. A cidade aparece cada vez mais fragmentada em seu tecido urbano, toma a forma de fragmentos separados de um espaço que não une quase nada e que representa novos terrenos para a urbanização. O objetivo deste artigo é identificar os principais determinantes da fragmentação no espaço geográfico da cidade hispano-americana. Para isso, foi empregada metodologia qualitativa que combina a revisão documental com a análise dos processos espaciais ocorridos durante as últimas cinco décadas nas cidades hispano-americanas. Os achados deste trabalho indicam que os principais determinantes da fragmentação no espaço geográfico são a fricção e a distância psicológica, social e econômica. Portanto, é necessária uma política urbana integral que minimize a fragmentação nessas cidades.

\section{PALAVRAS-CHAVE}

Urbanização; fragmentação urbana; novo modelo de cidade latino-americana; zonas industriais; industrialização por substituição de importações.

\section{CLASSIFICAÇÃO JEL}

J11, 018, R14, R31

\section{CONTEÚDO}

Introdução; 1. Princípio da fragmentação; 2. Fragmentação e globalização; 3. Conclusões; Bibliografia. 


\section{INTRODUCCIÓN. ANTECEDENTES DE LA FRAGMENTACIÓN}

La pregunta básica con la cual se desarrolla la hipótesis de este trabajo trata sobre la permanencia y duración del fenómeno de la fragmentación urbana y se basa en los estudios de la historia de la ciudad, las tendencias de su expansión territorial y sus cambios estructurales. Hasta los antiguos cuarteles romanos, en varias partes de Europa, tenían la forma y el uso del espacio ordenados, lo que nos permite suponer la existencia de las primeras muestras de la fragmentación: la parte del comando y la jefatura de los edificios donde vivían los soldados estaba separada espacialmente de espacio de servicios (Czerny y Czerny, 2018).

En la época colonial se crearon centros administrativos y comerciales en las ciudades fundadas por los españoles en América, y en ellas ya existía una segregación socio espacial muy acentuada, pero a la vez simple, que consistía sobre todo en las diferencias de estatus social entre los españoles y los nativos, lo que se reflejaba en modos de ocupación del espacio urbano por los grupos étnicos y sociales (Silva, 1997). Los españoles, que controlaban el poder político y económico colonial, ocupaban el centro, y los nativos, sirvientes, peones y campesinos se instalaban en la periferia de las nuevas ciudades formadas siguiendo el plano de ajedrez. Así, la estructura espacial y social de las ciudades españolas era bipolar (Czerny, y Czerny, 2020).

La primera mitad del siglo XX trajo muchos cambios en la estructura espacial, los cuales fueron causados por la llegada de nuevos inmigrantes europeos a América Latina (Wilhelmy y Borsdorf, 1984). Empresarios, comerciantes, artesanos y obreros europeos necesitaban viviendas para alojarse, ya que el antiguo orden espacial colonial fue roto y las manzanas coloniales decayeron en su forma y estructura interna (Czerny, 2014). La mayoría de las casas coloniales fueron vendidas a nuevos inmigrantes, divididas en pequeños lotes y vendidas o arrendadas a los nuevos ciudadanos quienes, en cierto modo, no disponían de muchos recursos económicos, pero por sus habilidades económicas desarrolladas en su nuevo lugar de vida (comercio, pequeños talleres) decidieron quedarse en el centro (Czerny y Czerny, 2020). Así, en lugares de antiguos patios aparecieron nuevas calles y urbanizaciones, a menudo precarias o no bien acabadas. Además, inició el proceso de transformación del espacio urbano de bipolar a tripolar, de criollos, empresarios (sobre todo pequeños) y nativos sin poder económico (Santos, 1990). Igualmente, se empezó a dividir y diversificar el área urbanizada. Al lado de casas coloniales y chacras de los nativos de las periferias urbanas, aparecieron espacios transformados con usos del suelo más densos y diversificados con múltiples funciones económicas no rurales (Wilhelmy y Borsdorf, 1984). 
A partir de la segunda mitad del siglo XX más precisamente, desde los años setenta de dicho siglo, junto con una enorme dinámica urbana que trajo como consecuencia el acelerado crecimiento de la población urbana y de la mancha urbana, empezó el proceso de construcción de retazos dentro de la superficie urbana (Valenzuela, 2013). Ante la necesidad de servir y manejar a una población mucho más grande, se crearon subcentros fuera del centro tradicional, se separaron barrios de diferentes clases sociales y se establecieron zonas industriales y de servicios en gran escala (Czerny, 2018). La sociedad eligió actuar y estar presente solo en unas partes de la ciudad y no en otras (Czerny y Czerny, 2018). Así empezó el periodo de ruptura de las relaciones espaciales, no había intercambios entre habitantes de los barrios ricos y de los pobres (no hubo necesidad de buscar el trabajo); los ricos dejaron de visitar el centro histórico que, abandonado y descuidado, dejó de jugar el papel integrador de la sociedad urbana y de escaparate de la ciudad (Czerny y Czerny, 2020). Muchos de estos centros se convirtieron, por más de tres décadas, en tugurios y en centros de actuación del sector informal (Alvarado-Rosas, GómezMaturana e Hidalgo- Dattwyler, 2016). De esta manera empezó la etapa de creación y de formación de la ciudad multipolar, aunque todavía no representa el esquema multifocal y multifuncional que se observa el día de hoy y de lo cual se hablará más adelante. Desde el punto de vista analítico, este esquema y los procesos de focalización de funciones lo representan mejor los modelos y esquemas ideales de las ciudades latinoamericanas elaborados y publicados por geógrafos desde mediados de los años setenta del siglo XX (Wilhelmy y Borsdorf, 1984).

El proceso de fragmentación de la mancha urbana ha provocado la intensificación de las investigaciones sobre los modelos de ciudades latinoamericanas realizadas por geógrafos urbanos (Czerny y Czerny, 2020). El periodo de interesantes trabajos sobre segregación socio-espacial fue durante las décadas de 1970 y 2000 (Valenzuela, 2013). Dichos modelos presentaron a la ciudad como un territorio bien dividido entre clase alta, media y baja; la última ocupaba el grupo más grande de las ciudades antes del año 2000 (Wilhelmy y Borsdorf, 1984; Alvarado-Rosas et al., 2016). Sin embargo, la ciudad estuvo todavía en cierto modo ordenada, o sea, posibilitaba para construir esquemas con secciones internas funcionales y sociales bien marcadas en su territorio (Santos, 1990; Czerny, 2014). Este ha sido el rasgo más característico de las ciudades latinoamericanas en las últimas tres décadas del siglo XX: un gran espacio ocupado por viviendas precarias, no acabadas, en un estado de construcción permanente, sin infraestructura y facilidades adecuadas, con grandes distancias por superar entre el lugar de vivienda y los lugares de trabajo. Además, como consecuencia de la introducción de la estrategia de industrialización por sustitución de importaciones en toda la región, se establecieron zonas industriales en las ciudades 
grandes (Czerny, 2007). Por lo general, formaron conjuntos (aglomeraciones) bien marcados en el espacio, apoyadas por las políticas de creación de varios tipos de parques. Las zonas o ciudades industriales se convirtieron en elementos estables de la división funcional y territorial de las ciudades grandes y su presencia estuvo marcada en todos los modelos y esquemas ideales de las ciudades latinoamericanas desde 1975 hasta fines del siglo XX (Valenzuela, 2013; Czerny, 2014; Czerny 2018).

La situación interna y el esquema socio-funcional en el espacio físico de las ciudades empezaron a cambiar desde principios del siglo XXI (Judd, 2003). Los primeros autores que indicaron en sus trabajos dichos cambios fueron Borsdorf, Bähr y Janoschka (2002). En su trabajo sobre el cambio estructural de la ciudad latinoamericana mostraron por primera vez el nuevo concepto de dicha ciudad: la ciudad fragmentada. A dicha idea se hará referencia más adelante para confrontarla con las observaciones e ideas propias.

\section{PREMISA DE LA FRAGMENTACIÓN}

¿Qué es entonces la fragmentación? ¿Qué significa ser fragmentado en la realidad urbana? ¿Cuáles son o pueden ser las consecuencias del proceso de fragmentación para la urbe? ¿Hasta qué nivel de dispersión puede llegar la fragmentación? Partiendo de la premisa de que la ciudad es un organismo social muy diversificado por su morfología y fisionomía, se considera que la fragmentación constituye la imagen y, al mismo tiempo, el resultado de los procesos, cada vez más dinámicos, dentro de la urbe (Czerny, 2005).

¿Puede considerarse que los procesos contemporáneos de la fuerte dinámica de todo tipo de inversiones dispersas en el espacio urbano conducen a la fragmentación? ¿Es posible que dicha fragmentación (el proceso de localizar edificios y conjuntos urbanos de varios tipos del uso y de diferentes funciones de manera poco controlada por la planificación urbana y dirigida por los procesos capitalistas de la competencia por la tierra urbana) produzca un caos urbano? ¿Qué significaría entonces este caos? ¿No es un proceso normal de la dinámica urbana de la ciudad donde domina la economía liberal? ¿Cuáles son los mecanismos y actores influyentes en dicha fragmentación?

Se puede buscar y mencionar un número significativo de factores-manifestaciones importantes, causantes y resultantes tanto del caos urbano como de la matriz del uso del suelo urbano, que toma la forma de patchwork, mucho más desordenada y caótica, que la que habíamos observado en la década de los años noventa del siglo XX (Czerny, 2014). 
Con base en varios estudios realizados en las ciudades latinoamericanas, entre ellos el de Prévot (2001), a continuación se mencionan los factores más influyentes y sus manifestaciones - aunque, por supuesto, no es una lista completa-. Espontaneidad de la expansión urbana, baja calidad de la mayoría de las construcciones, riesgos ecológicos provocados por el desarrollo excesivamente agresivo de áreas de alto riesgo, varios niveles de abastecimiento en servicios, carencias en cuanto a la cantidad y calidad del transporte público, planificación urbana insuficiente, marginalización social, y el fuerte factor cultural que va dando forma al espacio urbano (Czerny, 2014).

a. El primer factor es la expansión del área urbana espontánea sin control y límites tanto formales como geográficos. Este proceso se observa en todas las regiones de América Latina (Czerny y Czerny, 2018). Esta espontaneidad, a primera vista, no siempre es espontánea, sino guiada por los intereses inmobiliarios de las grandes constructoras por las políticas municipales y metropolitanas sobre la repartición y el uso del suelo urbano (Prévot, 2001). Sin embargo, un cuadro muy común en las ciudades latinoamericanas son los lotes de construcción marcados en el terreno todavía no urbanizado o con síntomas de una urbanización, muchas veces muy alejada del centro de su ciudad (Czerny, 2018).

En este caso no se trata del proceso de suburbanización clásica ni tampoco de urban sprawl, propia del crecimiento urbano en ciudades norteamericanas (Gutry Korycka, 2005; Czerny 2005; Prévot, 2001). Más bien, se puede hablar de prolongación artificial en la forma de áreas dispersas inadecuadas para la clase media del área urbana. De esta manera, se satisface la demanda de vivienda (aunque rudimentaria) de los estratos sociales más bajos y pobres, muchas veces de los recién llegados inmigrantes del campo o desplazados de zonas de mucho interés en donde hay planes de explotación de recursos naturales (Czerny y Czerny, 2020). Este fenómeno se aplica principalmente en las zonas urbanas y suburbanas menos atractivas para empresas constructoras. Son terrenos de especulación en donde no se aplica, en principio, ninguna política urbana o se introduce más tarde, cuando la urbanización ya está más o menos consolidada. Esta situación se ilustra en los gráficos 1 y 2. 
Gráfico 1. Arequipa. Lotización de tierras con suelos pedregosos, localizadas más arriba de la ciudad, con difícil acceso al centro y a los lugares de trabajo

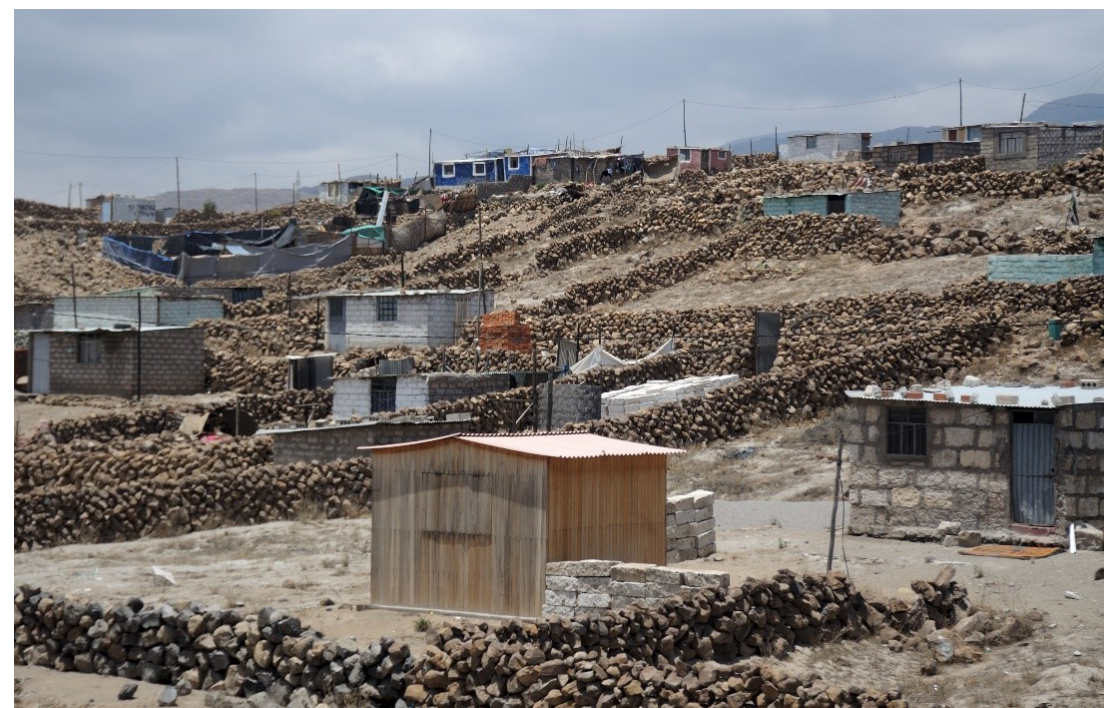

Fuente: Mroslawa Cerny, archivo personal.

Gráfico 2. Lima. Periferias de la ciudad con carencias para un asentamiento humano, donde viven inmigrantes del campo recién llegados

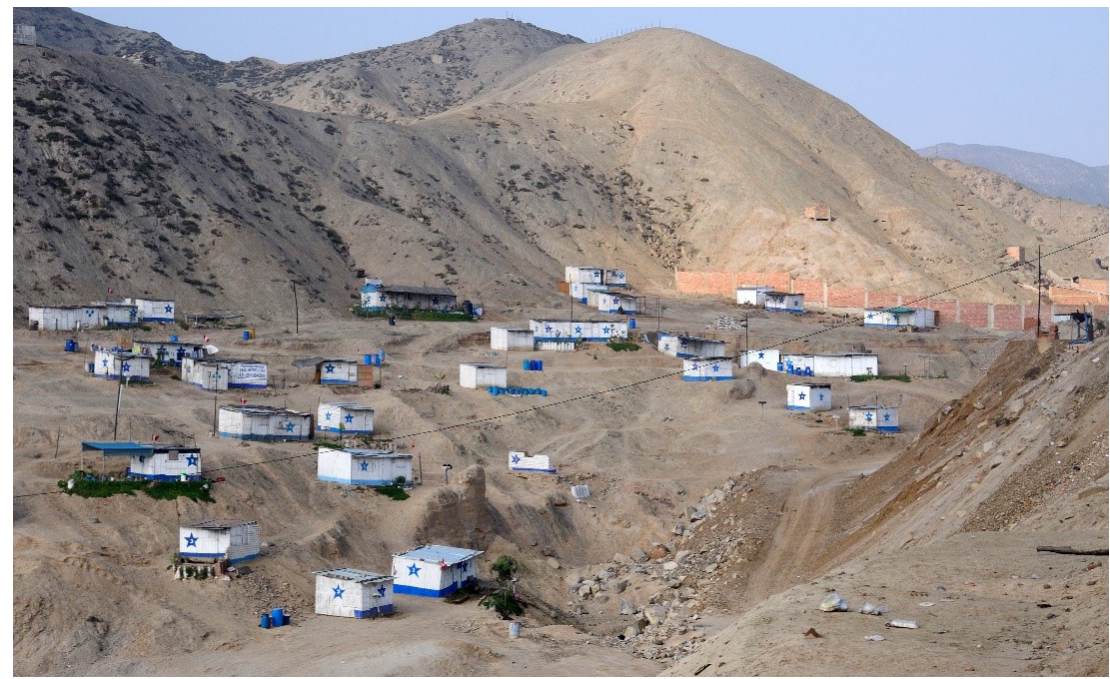

Fuente: Miroslawa Czerny, archivo personal. 
b. El segundo factor es la dominación de construcciones de baja calidad con respecto al material de construcción, al estilo arquitectónico y al acabado (Prévot, 2001). Aunque no es un paisaje monótono, sino muy diversificado por las residencias de los distintos subgrupos de diferentes clases sociales dispersas por las zonas urbanas, este factor se refiere, sobre todo, a las urbanizaciones de las clases sociales medias, medias bajas y bajas (Gutry-Korycka, 2005). También este tipo de construcciones se encuentra en la periferia semiurbanizada y suburbanizada, con frecuencia en las zonas de expansión hacia terrenos agrícolas. En las zonas suburbanas, a menudo se construyen casas provisionales que, con el transcurso del tiempo, se convierten en más sólidas y mejoradas (Czerny, 2014). Además, el uso del lote inicialmente tiene rasgos de uso campesino y no urbano (corrales, pequeñas áreas de cultivos, uso mixto, etc.). Este fenómeno se ilustra en el gráfico 3.

\section{Gráfico 3. Toluca. Municipios periféricos de Toluca sujetos a procesos intensos de suburbanización}

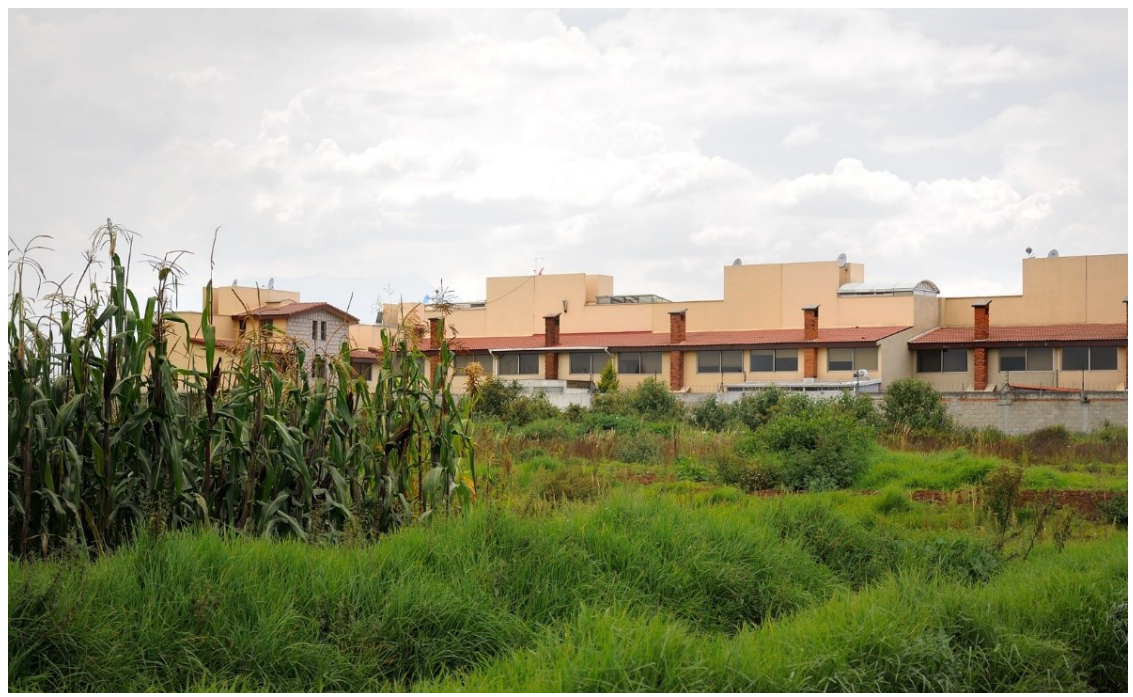

Fuente: Miroslawa Czerny, archivo personal.

c. El tercer factor tiene que ver con los desastres y riesgos ecológicos causados por la expansión urbana no controlada o por la falta de planeación; y la expansión descontrolada en zonas donde nunca se debió permitir construcciones de viviendas (Prévot, 2001). Tales zonas están expuestas a inundaciones, lodos o deslizamientos de tierra en las laderas poco estables y en las urbanizaciones cerca de vertederos donde hay una amenaza por las sustancias químicas emitidas y otros desechos. 
d. El cuarto factor es la diferenciación espacial en cuanto al abastecimiento en servicios e infraestructura urbana (Czerny, 2014). En relación con este factor resalta la falta de servicios urbanos completos, cierto abandono de varias partes de la ciudad en cuanto al suministro y provisión de muchas facilidades necesarias para los residentes.

e. El quinto factor tiene que ver con problemas con el transporte público, la posición periférica (física y psicológica) de varios sectores urbanos por falta del rápido y cómodo acceso de sus habitantes hasta el centro y a otras partes de la ciudad.

f. El sexto factor es la planificación urbana insuficiente, poco exigente, y caótica. Aunque en las últimas dos décadas ha mejorado mucho el proceso de planificación en varios países latinoamericanos (Czerny y Czerny, 2020). Se han introducido acciones consistentes en el mejoramiento del transporte urbano y el medio de la vida de sus habitantes.

g. El séptimo factor es la marginación social, la falta de integración de todos los grupos sociales en la discusión sobre nuevos proyectos y necesidades urbanas (Czerny y Czerny, 2018). Se les excluye del proceso de consulta popular o se maneja de tal manera que la voz de los grupos sociales marginados no es tomada en cuenta ni considerada en un discurso público. La debilidad institucional de gran parte de los habitantes favorece a los inversionistas y grupos de poder en cuanto al manejo del espacio urbano (Czerny, 2018).

h. Por último, está el factor cultural y las costumbres que apoyan la concentración y agrupación de los habitantes según etnia u origen de procedencia regional (Czerny, 2014). Los inmigrantes provenientes del mismo pueblo o de la misma zona buscan la vecindad entre sí y, por lo general, se establecen en lugares concretos, con direcciones conocidas dentro del espacio urbano. Se ha observado en varias ciudades latinoamericanas que los inmigrantes rurales se agrupan en las urbes y escogen barrios donde ya se habían instalado sus parientes o compadres (Czerny, 2018). Ellos les facilitan su instalación en un lugar nuevo y les apoyan durante los primeros días o semanas en la ciudad (Czerny y Czerny, 2020).

A pesar de los factores arriba mencionados, hay un gran número de actores que, en diferentes lugares y con variadas fuerzas, contribuyen a la desintegración de la ciudad, entendida tradicionalmente como un territorio compacto bajo varios criterios sociales, económicos y espaciales. De esta manera, se da una imagen común de lo caótico que es la urbe latinoamericana (Czerny 2014). 
Para los geógrafos urbanos uno de los temas más interesantes de la imagen de la ciudad es la fisionomía y morfología urbana (Czerny y Czerny, 2018). Son cuestiones bien reconocidas y analizadas por la geografía en diferentes contextos regionales y culturales (Borsdorf, Bähr y Janoschka, 2002). En este estudio dedicado a la fragmentación se distingue entre fragmentación espontánea, fragmentación semiespontánea y fragmentación institucionalizada. Por fragmentación espontánea se entiende la situación en la cual los fenómenos de expansión urbana, partiendo del centro (o un lugar de su localización) hacia la periferia, nunca han estado sujetos a fuerzas reguladoras y controles por parte de las instituciones formales o presionados por agentes inmobiliarios (Czerny, 2014). Los barrios y urbanizaciones, durante el transcurso del tiempo, por su propia dinámica, han podido desparramarse libremente alrededor del núcleo urbano. Sus formas y fisionomías han sido diversificadas, fragmentadas, separadas una de la otra en el espacio. Por el diseño de las formas y los modos de localización, se les puede considerar como sorprendentemente interesantes, ricos en artefactos para los análisis científicos. Dicha espontaneidad resulta de los factores económicos, sociales y culturales vinculados con historias regionales y urbanas, tanto del lugar de origen como del destino (Czerny y Czerny, 2018).

Por la fragmentación semiespontánea -según las proporciones de las clases sociales, intereses políticos y posibilidades adquisitivas de los ciudadanos- entendemos a los procesos parcialmente manejados por diferentes actores (Czerny, 2014). Entre otros, hay que mencionar a las inmobiliarias que, por ejemplo, compran terrenos de los grandes terratenientes, los lotizan y, según sus localizaciones y condiciones naturales, venden a los clientes, representantes de diferentes clases sociales. Históricamente, esta es la estructura urbana más permanente y segregacionista espacialmente (Czerny y Czerny, 2020). Cada vez más este tipo de fragmentación es apoyado por las decisiones político-administrativas gracias a las cuales se permite $\mathrm{o}$ limita el acceso a nuevos sitios para la construcción. Un ejemplo es el caso mexicano, donde gracias a los cambios reguladores de uso de las tierras ejidales introducidos en la década de los noventa del siglo XX en la Constitución y la liberalización del manejo de dichas tierras (Alvarado-Rosas et al., 2016), se impulsó enormemente el ya dinámico proceso de suburbanización y de urban sprawl (Gutry-Korycka, 2005). Este fenómeno se ilustra en el gráfico 3. 


\section{Gráfico 3. Mapa de urbanización en zona metropolitana de Toluca}

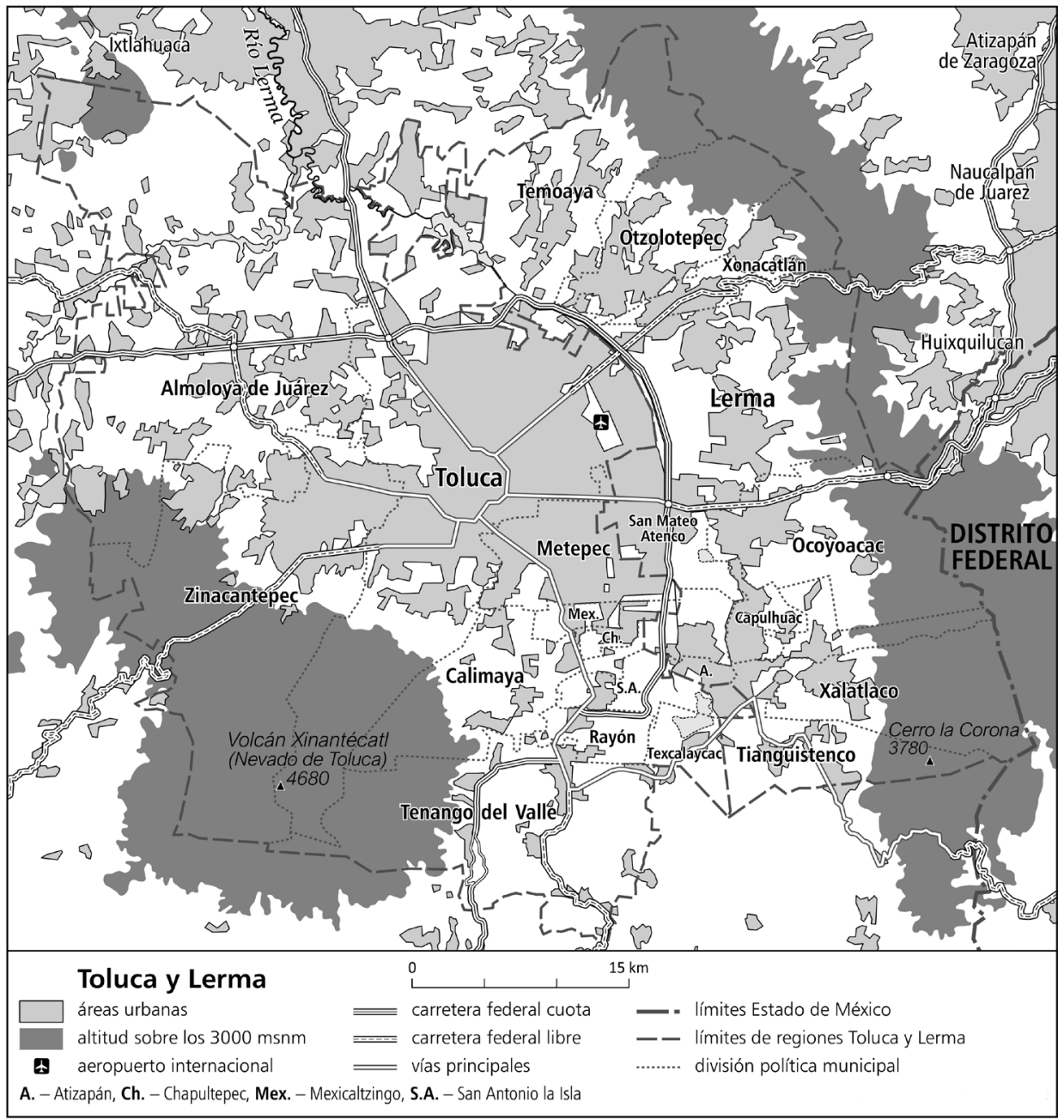

Fuente: elaboración propia a partir de Google Earth.

Por último, se tiene la fragmentación institucionalizada, la cual es mantenida por las regulaciones legales (Czerny, 2014). El caso clásico lo representan las ciudades colombianas (Bogotá y otras grandes). Allí, el sistema de estratificación introducido por el gobierno colombiano hace tres décadas ha demarcado claramente la localización de los barrios de diferentes estratos sociales (en total son seis). Por otro lado este proceso provocó cierta estabilidad de la estructura socio-espacial, pues los habitantes que viven en las zonas de estratos inferiores no siempre están interesados en cambiar el lugar de vivienda para no pagar más por los servicios 
(PNUD, 2007). Así madura y se mantiene la fragmentación institucionalizada en las ciudades colombianas (ver mapa de la estratificación en Bogotá). Esta situación se presenta en el gráfico 4.

\section{Gráfico 4. Mapa de estratificación en Bogotá (Colombia)}

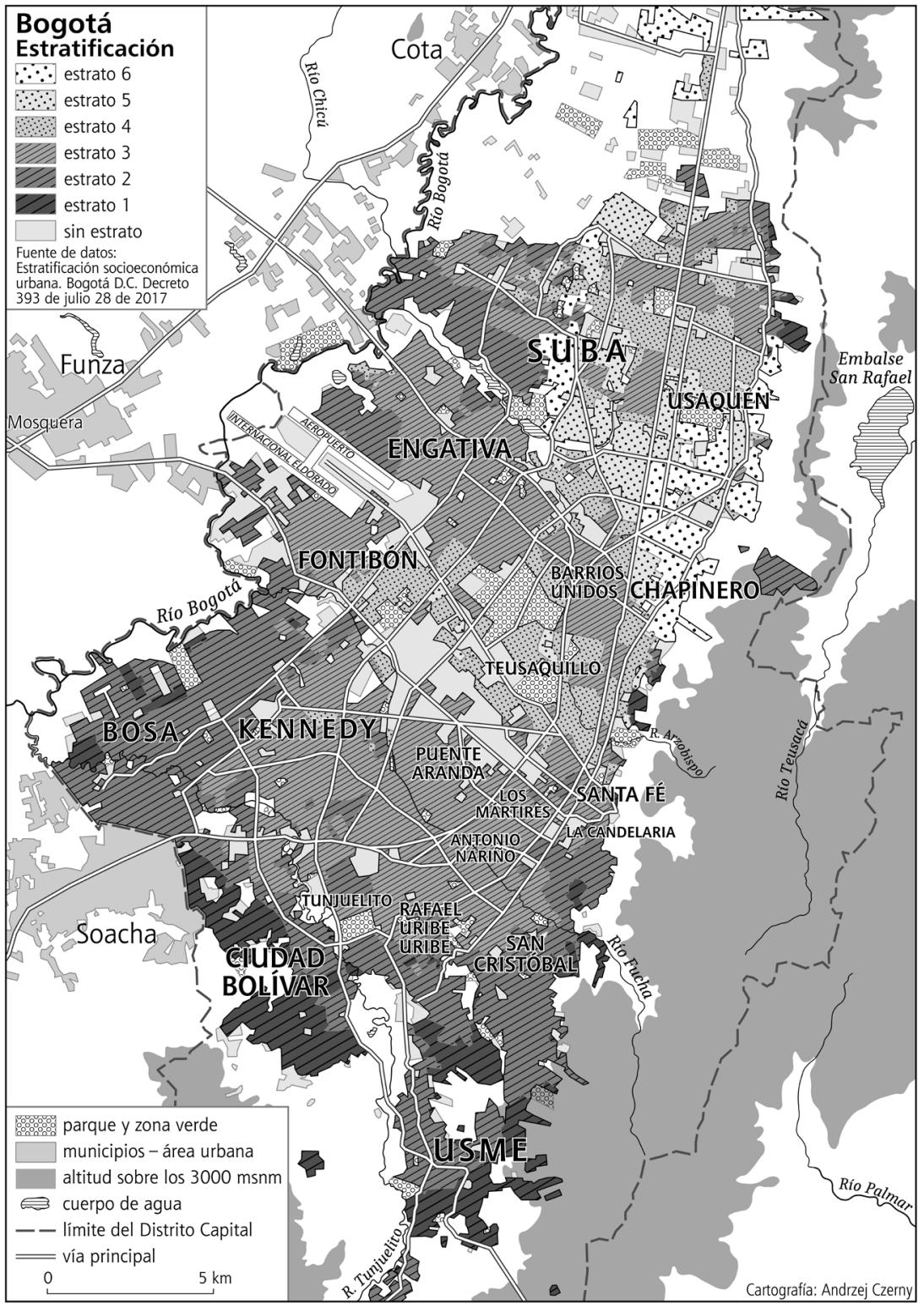

Fuente: elaboración propia a partir de Google Earth. 
Existen también otras normas legales que estructuran el uso del suelo urbano y crean la fragmentación semiinstitucionalizada o institucionalizada (Czerny, 2018). Curiosamente, también algunas reglas de planificación urbana pueden causar dicho efecto. Por ejemplo, la obligación de pagar impuestos por las casas terminadas hace que no se termine la construcción de la casa durante muchos años (Czerny, 2014). Esto ocurre especialmente en los barrios de clase baja (por ejemplo, en Perú). Otras regulaciones inducidas por las autoridades de planeación urbana hacen que se dejen vastos terrenos urbanos sin ningún uso (se trata sobre todo de terrenos pertenecientes al Estado o al municipio).

\section{FRAGMENTACIÓN Y GLOBALIZACIÓN}

Los artefactos, dispositivos, aparatos, símbolos y manifestaciones de la globalización generan la fragmentación socioterritorial de la ciudad desde el momento en que sus diversos segmentos se separan dentro su estructura espacial (Czerny 2007). Además, por la dominación en la esfera de arquitectura y de diseño, ciertas escuelas occidentales y ciertos talleres arquitectónicos en todas partes del mundo, repiten las mismas soluciones y patrones espaciales y urbanísticos (Valenzuela, 2013). Centros con rascacielos y edificios inteligentes cada vez más sofisticados se encuentran en la mayoría de las capitales nacionales del mundo (Davis, 2002). Grandes áreas de servicios con centros comerciales de cuarta y quinta generación, grandes espacios de estacionamientos, zonas de entretenimiento y hasta zonas deportivas constituyen, no solo los símbolos arquitectónicos de la globalización, sino también los nuevos símbolos del modo de vida (Czerny, 2007). Los habitantes de la ciudad, en vez de visitar centros coloniales, prefieren pasar el tiempo en estos "nuevos templos del consumo y entretenimiento". Solo los turistas dan vida a los centros históricos (González 2012; Czerny y Czerny, 2020).

Judd (2003) afirmaba que las ciudades están pasando por procesos de profunda transformación y están muy influenciadas por la globalización en cuanto a los estilos arquitectónicos, la organización de la estructura espacial y las soluciones infraestructurales. A esto se puede añadir los elementos del transporte urbano -su organización, formas, rutas, modos de organización; el papel del espacio público-, su arreglo, forma, concepto, función (González, 2012). Lo último está relacionado con los procesos de revitalización que posibilitan usar superficies antes ignoradas para plantar vegetación y producir espacios verdes (como techos y paredes).

Según Davis (2002), la imagen de la ciudad dividida, diversificada y triturada apoya el concepto de fragmentación, entendido como un conjunto de estructuras dominadas por procesos de desigualdad, exclusión social, segregación y 
tugurización que surgen de lo que algunos llaman ecología de miedo. Según esta, el sistema interior de la ciudad está subordinado a la creación y mantenimiento de la distancia de un grupo social al otro. Esto sucede con frecuencia en las ciudades latinoamericanas (Czerny, 2014; Czerny y Czerny, 2020). A este proceso lo apoyan viejas y nuevas relaciones muy limitadas entre grupos sociales, muchas veces hostiles, privadas de confianza, llenas de prejuicios que surgen de una profunda discriminación de unas clases frente a otras desde tiempos de la colonia (Silva, 1997; Czerny y Czerny, 2018).

\section{CONCLUSIONES}

Con estas observaciones de carácter cultural, psicológico y económico se puede suponer que uno de los atributos más importantes y, al mismo tiempo, determinantes de la fragmentación en el espacio geográfico es la fricción y la percepción de distancia (Czerny y Czerny, 2020). La distancia, no física sino social y psicológica, es la causa y el rasgo principal de la fragmentación urbana. Las causas de la distancia pueden ser culturales, sociales, políticas, económicas o naturales. En general son multifactoriales. En el caso de las ciudades latinoamericanas la distancia crea:

- Una ciudad sin armonía interna, dividida entre los sectores según la forma de vivir.

- División y segmentación según su imagen urbanístico morfológica y su arquitectura.

- Localización concreta en el espacio físico de los respectivos barrios y urbanizaciones.

- La falta (con pocas excepciones) de un transporte urbano integral igualado, por su acceso (y rutas) para toda la sociedad urbana.

- La discriminación de ciertos sectores en cuanto al acceso a otros servicios urbanos y la infraestructura urbana.

- Voz insuficiente y poco escuchada (mediante la participación social) de representantes de los barrios más alejados (periféricos).

De los casos estudiados, y con base en la revisión de las diferentes investigaciones que fueron consideradas en este trabajo, se puede concluir que todavía falta una política integral urbana, no tanto para eliminar la fragmentación, sino para suavizarla. De acuerdo con lo anterior se propone lo siguiente: 
- La aplicación de instrumentos legislativos, respecto al manejo de la tierra urbana, más restrictivos para omitir tan fuerte diversificación del estándar de las urbanizaciones.

- El planeamiento urbano basado en las ideas de la ciudad verde y abierta para todos.

- Una mejor organización de los espacios públicos, más grandes, con más elementos verdes, con más planeamientos culturales.

- La resignación de la construcción de rejas, barreras y otros tipos de cerramiento de los barrios.

La ciudad está formada por sus habitantes, el mercado y las instituciones. El correcto equilibrio entre estos actores hace que el espacio de la ciudad esté bien gestionado (es decir, formado de forma democrática). Este espacio también es más justo socialmente, ambientalmente sostenible y económicamente más efectivo, crea oportunidades, y la gente hace mejor uso de estos gracias a la correcta relación entre el poder y la sociedad. Un mercado desregulado en la asignación de inversiones y sin la participación ciudadana y de los mecanismos de gestión del ámbito local (de los distritos o barrios), no reducirá la fragmentación. Las inversiones en infraestructura básica y el acceso a los servicios de todas las clases sociales son claves para disminuir las diferencias espaciales existentes en las ciudades hispanoamericanas del siglo XXI.

\section{BIBLIOGRAFÍA}

Alvarado-Rosas, Concepción; Gómez-Maturana, Ricardo e Hidalgo-Dattwyler, Rodrigo (Coords.) (2016). Expresión territorial de la fragmentación y segregación. Cuernavaca: Universidad Autónoma del Estado de Morelos, 305 p.

Borsdorf, Axel; Bähr, Jürgen y Janoschka, Michael (2002). Die Dynamik stadtstrukturellen Wandels in Lateinamerika im Modell der lateinamerikanischen Stadt. En: Geographica Helvetica, vol. 57, n. ${ }^{\circ}$, p. $300-310$.

Czerny, Miroslawa y Czerny, Andrzej (2020). Conferencia de geógrafos latinoamericanistas. Antigua: CLAG.

Czerny, Miroslawa (2018). Las ideas sobre ciudades latinoamericanas de Milton Santos - 50 años después. 35. ${ }^{a}$ Conferencia de Geógrafos Latinoamericanistas (CLAG). San José: CLAG.

Czerny, Miroslawa y Czerny, Andrzej (2018). Regularny układ przestrzenny miasta latynoamerykańskiego -historia i rozwój [El modelo espacial regular de la ciudad latinoamericana -historia y desarrollo]. En: Studia z Geografii Politycznej i Historycznej, vol. 6, p. 19-34. DOI: $10.18778 / 2300-0562.06 .01$ 
Czerny, Miroslawa (2014). Stare i nowe w przestrzeni miast Ameryki Łacińskiej IViejo y nuevo en el espacio de las ciudades Latinoamericanas]. Varsovia: Publikacja dostępna, 225 p.

Czerny, Miroslawa (2007). Globalizacja a rozwój [Globalización y desarrollo]. Varsovia: Wydawnictwo Naukowe PWN, 272 p.

Czerny, Miroslawa (2005). From city periphery to urban sprawl -Word experiences. En: Gutry-Korycka, Malgorzata (Ed.). Urban Sprawl. Warsaw Agglomeration Case Study. Varsovia: Warsaw University Press, p. 21-36.

Davis, Mike (2002). Más allá de Blade Runner. La ecología del miedo. Barcelona: Virus Editorial, $72 \mathrm{p}$.

González, Fernando (2012). Apuntes sobre la ciudad fragmentada y sus espacios públicos. En: Boletín Espacio Diseño, n. 204 , p. 23-27.

Gutry-Korycka, Malgorzata (Ed.) (2005). Urban Sprawl. Warsaw Agglomeration Case Study. Varsovia: Warsaw University Press, 335 p.

Judd, Dennis (2003). El turismo urbano y la geografía de la ciudad. En: Eure, vol. 29, n. ${ }^{\circ}$ 87, p. 51-62. DOI: http://dx.doi.org/10.4067/S0250-71612003008700004

PNUD Colombia. Programa de las Naciones Unidas para el Desarrollo (2007). El uso del suelo: un gran desafío para Bogotá. Bogotá: PNUD Colombia, 128 p.

Prévot, Marie-France (2001). Fragmentación espacial y social: conceptos y realidades. En: Perfiles Latinoamericanos, vol. 9, n. ${ }^{\circ}$ 19, p. 33-56.

Santos, Milton (1990). Métropole corporativa fragmentada: o caso de Sâo Paulo. San Pablo: Nobel, $117 \mathrm{p}$.

Silva, Marta Beatriz (1997). Las dimensiones urbanas. Los patrones coloniales y decimonónicos. Recuperado de https://bit.ly/2WrDWTk

Valenzuela, Alfonso (2013). Dispositivos de la globalización: la construcción de grandes proyectos urbanos en Ciudad de México. En: Eure, vol. 39, n. ${ }^{\circ} 116$, p. 101-118.

Wilhelmy, Herbet y Borsdorf, Axel (1984). Die Städte Südamerikas. Teil 1. Wesen und Wandel. Berlín: Borntraeger, 233p. 